\title{
Rancang Bangun Sistem Pakar Penentuan Kepribadian
}

\author{
Roki Hardianto ${ }^{1}$, Chandra Kusuma ${ }^{2}$ \\ ${ }^{1}$ Fakultas Ilmu Komputer, Teknik Informatika, Universitas Lancang Kuning, Pekanbaru, Indonesia \\ ${ }^{2}$ Komputerisasi Akuntansi, STMIK Dharmapala, Riau, Indonesia \\ Email: roki@unilak.ac.id, chandrakusuma2015.ck23@gmail.com
}

\begin{abstract}
Abstrak-Dengan perkembangan teknologi setiap waktu ke waktu, semua lini kehidupan sudah terkomputerisasi. Begitu juga sebuah system pakar penentuan tipe kepribadian yang bisa membantu psikolog dalam menyelesaikan tugasnya dengan cepat, tepat dan mudah. Disamping itu kurangnya jumlah psikolog dalam menangani kasus analisa tipe kepribadian manjadi catatan penting mengapa sebuah system pakar berbasis penentuan kepribadian dibutuhkan. Dalam penelitian ini system pakar yang dibangun menggunakan antar muka desktop yang juga bisa berbasis online. Tidak saja ketika berjumpa psikolog bisa digunakan tetapi juga bisa digunakan siapa saja menggunakan PC atau smartphone. Penelitian ini menggunakan metode Case Based Reasoning, dimana metode ini adalah metode yang cocok dalam perumusan knowledge yang baru terhadap pemeriksaan pasien dibidang ilmu psikologi. Merujuk kepada sebuah penelitian yang dilakukan oleh Florence Littauer yang membagi tipe kepribadian kepada 4 bagian yaitu Melankolis, Saguinis, Koleris dan Plegmatis. Diharapkan dengan penelitian ini bisa membantu pasien dan psikolog dalam menganalisa dan menentukan kepribadian dengan tepat, cepat dan mudah.
\end{abstract}

Kata Kunci: Sistem Pakar, Cased Based Reasoning, Kepribadian, Psikologi, Sistem Informasi

\begin{abstract}
Abstrack-With the development of technology every time, all lines of life are computerized. Likewise, an expert system for determining personality types can help psychologists complete their tasks quickly, precisely and easily. Besides the lack of psychologists in handling cases of personality type analysis is an important note why an expert-based expert determination system is needed. In this study an expert system that was built using a desktop interface can also be based online. Not only when you meet a psychologist you can use it, but you can also use anyone using a PC or smartphone. This research uses the Case Based Reasoning method, where this method is a suitable method in the formulation of new knowledge of the examination of patients in the field of psychology. Referring to a study conducted by Florence Littauer who divided personality types into 4 parts namely Melancholy, Saguinis, Koleris and Plegmatis. It is hoped that this research can help patients and psychologists in analyzing and determining their personality precisely, quickly and easily.
\end{abstract}

Keywords: Expert System, Cased Based Reasoning, Personality, Psychology, Information System

\section{PENDAHULUAN}

Dalam kehidupan sehari-hari, banyak kita jumpai sikap dan tingkah laku seseorang berbeda antar manusia. Hal ini dikarenakan setiap manusia mempunyai kepribadian yang unik. Psikologi sebagai rumpun ilmu membahas tentang kepribadian manusia. Didalam dunia kerja, dalam merekrut tenaga kerja yang baru tes kepribadian menjadi penilaian utama dalam seleksi. Maka dari pada itu mengenali kepribadian sejak dini sangatlah penting. Sebenarnya dalam proses mengenali kepribadian sejak dini sebagai orang tua kepada anak akan berdampak positif, karena dengan adanya mengenali kepribadian anak sejak dini dapat membantu orang tua dalam mengenali minat dan bakat anak sejak dini. Dalam kehidupan sehari-hari orang tua harus bisa mengontrol pola tingkah laku anak oleh karena itu orang tua perlu mengetahui tipe kepribadian dan potensi anak untuk masa depannya.

Sedangkan dalam perkuliahan seorang dosen harus mampu menguasai kelasa dengan tujuan tercapainya capaian perkuliahan yang telah disusun oleh dosen sebelum memulai perkuliahan dikelas. Kemudian daripada itu umur mahasiswa sangat menjadi faktor penting dalam mengenali kepribadian secara lebih cepat oleh dosen, kemudian pendekatan secara emosional oleh dosen menjadi faktor lain agar tujuan perkuliahan tercapai dengan baik. Begitu juga di tempat kerja kepribadian menjadi tolak ukur dalam proses penerimaan calon karyawan. Hal ini berguna dalam etos kerja dalam mewujudkan visi dan misi kerja dan keuntungan untuk kemajuan perusahaan.

Pada penelitian jurnal [1] mengangkat penelitian system pakar dengan objek penelitian tentang mengidentifikasi hama dan penyakit pada singkong menggunakan metode case based reasoning. Penelitian yang diangkat sekarang memiliki kesamaan dalam penggunaan metode tetapi berbeda dalam objek yang diteliti. Tentu artikel referensi ini bisa menjadi dasar dalam penyelesaian penelitian ini.

Sedangkan pada penelitian referensi jurnal [2] lebih tepat kepada bagaimana peneliti merancang sebuah system informasi yang bisa memudahkan dalam pencatatan data secara komputerisasi. Hal ini tentu sangat membantu peneliti dalam menyelesaikan jurnal ini, karena pada penelitian ini terdapat proses rancang bangun system informasi system pakar.

Pada penelitian di jurnal [3] yang mengangkat tema system pakar mendiagnosa penyakit Tuberkolosis dengan metode Forward Chaining, jelas penelitian ini ada kemiripan dengan penelitian yang saya angkat pada jurnal ini tetapi berbeda objek dan metode yang digunakan. Referensi yang bisa diambil peneliti terhadap penelitian jurnal ini adalah bagaimana membangun system informasi dan pengolahan data dengan mengunakan metode pada system pakar. Pada jurnal [4] yang ditulis oleh Hengki Tamando Sihotang menjelaskan bagaimana penelitiannya akan penyakit kolesterol yang tinggi terhadap remaja yang menggunakan metode certainty factor (CF) merupakan metode yang mendefinisikan ukuran kapasitas terhadap suatu fakta atau aturan, dalam mengekspresikan tingkat keyakinan seorang pakar terhadap suatu masalah yang sedang dihadapi, certainty factor 
(CF) memperkenalkan konsep belief atau keyakinan dan disbelife atau ketidakyakinan. Oleh karena itu agar tidak ada kesalahan diagnosa dan mempermudah masyarakat untuk mengetahui sejak dini penyakit yang diderita nada anak dan agar tidak terlambat mendapatkan pengobatan dikarenakan seorang dokter atau pakar memiliki keterbatasan waktu. Sedangkan pada jurnal terakhir [5] ini peneliti menggambil referensi karena system pakar yang diteliti sedikit ada kemiripan dengan yang peneliti lakukan penelitian dalam keilmuan psikologi tentang bakat anak. Dimana dilakukan analisa kepada anak akan bakat yang ada melalui rule-rule yang telah ditetapkan melalui metode Certauinty Factor yang dituangkan kedalam sebuah system informasi. Begitu juga topic yang diangkat peneliti dalam penelitian ini.

Dalam penelitian ini peneliti menitik beratkan referensi kepada 4 tipe kepribadian yakni Melankolis, Plegmatis, Koleris dan Sanguinis. Dengan alasan tipe kepribadian tersebut adalah tipe kepribadian yang umum dalam dunia psikologi. Diharapkan output dari penelitian ini bisa membantu penelitian lanjuta, pasien, masyarakat umum dan psikologi dalam mengambil sebuah kesimpilan terhadap suatu pokok permasalahan khususnya dalam penentuan kepribadian baik kepada orang dewasa maupun anak-anak.

\section{METODE PENELITIAN}

Pada pelaksanaan penelitian metode yang digunakan adalah metode pengamatan, penilaian dan kuisioner kepada mahasiswa dilingkungan fakultas ilmu komputer Universitas Lancang Kuning.

a. Metode Pengamatan

Dengan melihat hasil belajar mahasiswa, hal itu dilakukan dengan melakukan pembelajaran secara manual dan online dalam 1 - 2 semester kepada mahasiswa dengan pedoman kepada hasil pembelajaran. Melakukan tanya jawab dalam kelas saat pembelajaran dilakukan

b. Metode Penilaian

Ini dilakukan merupakan lanjutan dari metode pengamatan. Hasil lembaran kerja siswa dari tugas, kuis, ujian tengah semester dan ujian akhir semester menjadi pengamatan dari yang menggunakan dan tidak menggunakan blended learning.

c. Metode kuisioner

Pada metode ini mahasiswa mengisi langsung kuisiner yang telah disiapkan oleh peneliti. Mahasiswa akan menjawab pertanyaan yang diajukan peneliti. Kuisioner dapat berupa hasil cetakan dalam kertas atau kuisioner dibuat secara online yang disediakan oleh pihak ke tiga.

Pada penelitian ini metode yang digunakan adalah Case Based Reasoning yang mana pada CBR ini memiliki 4 tahapan diantaranya :

a. Retrieve

Tahapan ini merupakan awal dari penggunaan metode CBR. Awal prosesnya adalah pengguna akan memilih atau menginput gejala-gejala sikap dan tingkah laku manusia kesehariannya. Selanjutnya akan diproses oleh sistem dengen mencocokan kasus-kasus lama yang memiliki nilai kemiripan yang hampir sama. Pada saat pencocokan inilah digunakan perhitungan Case Based Reasoning pada ;

1. Proses pertama dicari terlebih dahulu nilai pada probabilitas dari tiap tipe kepribadian

2. Pada proses kedua setelah mendapatkan nilai probabiltas dari setiap tipe kepribadian barulah dicari probabilitas gejala yang sama

3. Pada proses ketiga dicari nilai probabbilitas dari semua tipe kepribadian

4. Proses berikutnya mencari nilai probabilitas gejala yang sama secara keseluruhan

5. Proses berikutnya mencari nilai akhir pada setiap kasusnya

6. Pada proses terakhir barulah dicari nilai probabilitas akhir penyakit

b. Reuse

Pada tahapan ini akan dipilih kasus termirip dengan nilai akurasi yang paling tinggi dan juga akan memunculkan solusi penanganannya.

c. Revise

Tahapan revise ini adalah proses yang seandainya pada proses retrieve menemukan gejala yang baru pada saat penginputan di proses awal nantinya terlebih dahulu akan dicek oleh pakar sebagai bahan untuk dipertimbangkan

d. Retain

Setelah mendapatkan solusi yang benar -benar tepat dari pakarnya barulah dimasukan kembali ke dalam basis pengetahuan yang dapat berguna untuk digunakan pada kasus-kasus yang akan datang.

\section{ANALISA DAN PEMBAHASAN}

Berikut ini adalah data yang telah diperoleh dari hasil wawancara dengan Psikologi dan studi literatur kepada buku dan jurnal mengenai tipe kepribadian dan gejala-gejalanya. Data tipe kepribadian dapat dilihat pada tabel 5.1 sebagai berikut (Sumber: Tes Personalitas Florence Littauer): 
Tabel 1. Tipe Kepribadian

\begin{tabular}{clc}
\hline No & Tipe Kepribadian & Kode \\
\hline 1 & Koleris & TK01 \\
2 & Sanguinis & TK02 \\
3 & Melankolis & TK03 \\
4 & Plegmatis & TK04 \\
\hline
\end{tabular}

Berikut ini adalah gejala gejala pada masing-masing tipe kepribadian yang digunakan. Selanjutnya gejala ini dijadikan sebagai rule dalam penelitian. Agar gejala bisa dipahami dalam bahasa mesin maka gejala ini kemudian dikonversi menjadi rule yang diinisialisasikan kepada kode berdasarkan tipe kepribadian. (Sumber: Tes Personalitas Florence Littauer).

Kemudian gejala-gejala dikelompokkan pada masing-masing tipe kepribadian yang telah dibahas diatas yang didapat dari soal tes kepribadian Florence Littauer. Agar dalam proses penentuan tipe kepribadian yang akan dirancang maka perlu gejala-gejala tersebut di terjemahkan kepada rule yang menjadi acuan sistem dengan nilai bobot berdasarkan gejala penting dan sedang / biasa. Nilai bobot gejala penting di beri bobot 5 sedangkan untuk gejala sedang / biasa diberi bobot 3. Maka didapat nilai masing-masing gejala dari tipe kepibadian seperti tabel berikut (Sumber: Tes Personalitas Florence Littauer) :

Tabel 2. Bobot Gejala Tipe Kepribadian Koleris

\begin{tabular}{|c|c|c|c|}
\hline No & Koleris & ID Rule & Bobot \\
\hline 1 & Penuh semangat & $\mathrm{K} 1$ & 3 \\
\hline 2 & Mudah marah & $\mathrm{K} 2$ & 3 \\
\hline 3 & Independen & K3 & 3 \\
\hline 4 & Berjiwa pemimpin & K4 & 3 \\
\hline 5 & Produktif & K5 & 3 \\
\hline 6 & Suka menonjolkan diri & K6 & 3 \\
\hline 7 & Tidak sabar & K7 & 3 \\
\hline 8 & Suka berpendapat & K8 & 3 \\
\hline 9 & Pendirian kuat & K9 & 3 \\
\hline 10 & Suka memerintah orang lain & $\mathrm{K} 10$ & 3 \\
\hline 11 & Dominan & K11 & 3 \\
\hline 12 & Keras kepala & $\mathrm{K} 12$ & 3 \\
\hline 13 & Cepat dalam mengambil keputusan & K13 & 3 \\
\hline 14 & Terorganisir & K14 & 3 \\
\hline 15 & Tidak suka kompromi & K15 & 3 \\
\hline 16 & Suka petualang & K16 & 5 \\
\hline 17 & Berkemauan keras & K17 & 5 \\
\hline 18 & Kompetitif & K18 & 5 \\
\hline 19 & Optimis & K19 & 5 \\
\hline 20 & Tidak mau kalah & $\mathrm{K} 20$ & 5 \\
\hline 21 & Pemberani & $\mathrm{K} 21$ & 5 \\
\hline 22 & Percaya diri & $\mathrm{K} 22$ & 5 \\
\hline 23 & Gigih & $\mathrm{K} 23$ & 5 \\
\hline 24 & Kurang simpati & $\mathrm{K} 24$ & 5 \\
\hline 25 & Suka tantangan & $\mathrm{K} 25$ & 5 \\
\hline 26 & Berorientasi target & K26 & 5 \\
\hline 27 & Intoleran & $\mathrm{K} 27$ & 5 \\
\hline 28 & Suka mengatur & $\mathrm{K} 28$ & 5 \\
\hline 29 & Egois & K29 & 5 \\
\hline 30 & Berwibawa & K30 & 5 \\
\hline 31 & Tegas & K31 & 5 \\
\hline 32 & Mandiri & K32 & 5 \\
\hline 33 & Sulit mengakui kesalahan & K33 & 5 \\
\hline
\end{tabular}

Tabel 3. Bobot Gejala Tipe Kepribadian Sanguinis

\begin{tabular}{clcc}
\hline No & \multicolumn{1}{c}{ Sanguinis } & ID Rule & Bobot \\
\hline 1 & Senang bergaul & S1 & 3 \\
2 & Ramah & S2 & 3 \\
3 & Meyakinkan & S3 & 3 \\
4 & Spontan & S4 & 3 \\
5 & Butuh perhatian & S5 & 3 \\
\hline
\end{tabular}




\begin{tabular}{clcl}
\hline 6 & Inspiratif & S6 & 3 \\
7 & Demonstratif & S7 & 3 \\
8 & Tidak terorganisir & S8 & 3 \\
9 & Butuh dukungan & S9 & 3 \\
10 & Pelupa & S10 & 3 \\
11 & Kurang bisa dikritik & S11 & 3 \\
12 & Ekspresif & S12 & 3 \\
13 & Emosi labil & S13 & 3 \\
14 & Naif & S14 & 3 \\
15 & Responsif & S15 & 3 \\
16 & Rasa ingin tahu tinggi & S16 & 3 \\
17 & Berjiwa sosial tinggi & S17 & 3 \\
18 & Kekanak - kanakan & S18 & 5 \\
19 & Inovatif & S19 & 5 \\
20 & Penuh semangat & S20 & 5 \\
21 & Hangat & S21 & 5 \\
22 & Humoris & S22 & 5 \\
23 & Suka menyenangkan orang lain & S23 & 5 \\
24 & Riang & S24 & 5 \\
25 & Kreatif & S25 & 5 \\
26 & Lincah & S26 & 5 \\
27 & Populer & S27 & 5 \\
28 & Kurang produktif & S28 & 5 \\
29 & Kurang disiplin & S29 & 5 \\
30 & Serba membolehkan & S30 & 5 \\
31 & Banyak bicara & S31 & 5 \\
32 & Tidak konsisten & S32 & 5 \\
33 & Pamer & S33 & 5 \\
\hline
\end{tabular}

Tabel 4. Bobot Gejala Tipe Kepribadian Melankolis

\begin{tabular}{clcc}
\hline No & \multicolumn{1}{c}{ Melankolis } & ID Rule & Bobot \\
\hline 1 & Suka berkorban & M1 & 3 \\
2 & Peduli & M2 & 3 \\
3 & Tidak mau disalahkan & M3 & 3 \\
4 & Disiplin & M4 & 3 \\
5 & Setia & M5 & 3 \\
6 & Musikal & M6 & 3 \\
7 & Pendendam & M7 & 3 \\
8 & Teratur & M8 & 3 \\
9 & Sulit bersosialisasi & M9 & 3 \\
10 & Sulit mempercayai orang lain & M10 & 3 \\
11 & Pesimis & M11 & 3 \\
12 & Serius & M12 & 3 \\
13 & Kaku & M13 & 3 \\
14 & Penakut & M14 & 3 \\
15 & Curiga & M15 & 3 \\
16 & Lamban dalam menerima hal baru & M16 & 3 \\
17 & Analitis & M17 & 5 \\
18 & Gigih & M18 & 5 \\
19 & Perencana & M19 & 5 \\
20 & Tertib & M20 & 5 \\
21 & Detail & M21 & 5 \\
22 & Kreatif & M22 & 5 \\
23 & Idealis & M23 & 5 \\
24 & Menarik diri & M24 & 5 \\
25 & Setia & M25 & 5 \\
26 & Perfeksionis & M26 & 5 \\
27 & Teliti & M27 & 5 \\
28 & Pendiam & M28 & 5 \\
29 & Mudah tersinggung & M29 & 5 \\
30 & Suka menyendiri & M30 & 5 \\
\hline & & &
\end{tabular}




\begin{tabular}{llll}
\hline 31 & Kritis & M31 & 5 \\
32 & Sangat Fokus memikirkan sesuatu & M32 & 5 \\
33 & Mudah kecewa & M33 & 3 \\
\hline
\end{tabular}

Tabel 5. Bobot Gejala Tipe Kepribadian Plegmatis

\begin{tabular}{|c|c|c|c|}
\hline No & Plegmatis & ID Rule & Bobot \\
\hline 1 & Penurut & $\mathrm{P} 1$ & 3 \\
\hline 2 & Kurang bisa mengambil keputusan & $\mathrm{P} 2$ & 3 \\
\hline 3 & Pemalu & P3 & 3 \\
\hline 4 & Suka membantu & P4 & 3 \\
\hline 5 & Rendah hati & P5 & 3 \\
\hline 6 & Mudah bergaul & P6 & 3 \\
\hline 7 & Penengah & P7 & 3 \\
\hline 8 & Pendengar yang baik & P8 & 3 \\
\hline 9 & Kurang antusias & P9 & 3 \\
\hline 10 & Segan & $\mathrm{P} 10$ & 3 \\
\hline 11 & Penakut & $\mathrm{P} 11$ & 3 \\
\hline 12 & Suka dipuji & $\mathrm{P} 12$ & 3 \\
\hline 13 & Ragu-ragu & $\mathrm{P} 13$ & 3 \\
\hline 14 & Tidak suka memerintah & $\mathrm{P} 14$ & 3 \\
\hline 15 & Menghindari konflik & $\mathrm{P} 15$ & 3 \\
\hline 16 & Tidak suka menonjolkan diri & P16 & 3 \\
\hline 17 & Pencemas & $\mathrm{P} 17$ & 3 \\
\hline 18 & Tidak mudah dipengaruhi & $\mathrm{P} 18$ & 3 \\
\hline 19 & Sopan & P19 & 3 \\
\hline 20 & Suka dengan pekerjaan yang monoton & $\mathrm{P} 20$ & 3 \\
\hline 21 & Sulit mengatakan "Tidak" & $\mathrm{P} 21$ & 3 \\
\hline 22 & Tenang & $\mathrm{P} 22$ & 5 \\
\hline 23 & Pendiam & $\mathrm{P} 23$ & 5 \\
\hline 24 & Sabar & $\mathrm{P} 24$ & 5 \\
\hline 25 & Ramah & $\mathrm{P} 25$ & 5 \\
\hline 26 & Tidak tegas & $\mathrm{P} 26$ & 5 \\
\hline 27 & Toleran & $\mathrm{P} 27$ & 5 \\
\hline 28 & Butuh penerimaan & $\mathrm{P} 28$ & 5 \\
\hline 29 & Suka dengan rutinitas & P29 & 5 \\
\hline 30 & Kurang suka kejutan & P30 & 5 \\
\hline 31 & Teratur & P31 & 5 \\
\hline 32 & Sangat hati - hati & P32 & 5 \\
\hline 33 & Kurang inisiatif & P33 & 3 \\
\hline
\end{tabular}

Berikut ini adalah aturan dalam perhitungan tipe kepribadian berdasarkan bobot gejala yang telah ditetapkan diatas yang digambarkan dalam bentuk tabel

Tabel 6. Aturan Tipe Kepribadian Dan Gejalanya

\begin{tabular}{|c|c|c|}
\hline No & Aturan & Kesimpulan \\
\hline 1 & $\begin{array}{l}\text { IF jumlah profil koleris }>\text { jumlah profil sanguinis AND } \\
\text { jumlah profil koleris }>\text { jumlah profil melankolis AND } \\
\text { jumlah profil koleris }>\text { jumlah profil plegmatis THEN } \\
\text { "Koleris" }\end{array}$ & $\begin{array}{c}\text { TP01 } \\
\text { KOLERIS }\end{array}$ \\
\hline 2 & $\begin{array}{l}\text { IF jumlah profil sanguinis }>\text { jumlah profil koleris AND } \\
\text { jumlah profil sanguinis }>\text { jumlah profil melankolis AND } \\
\text { jumlah profil sanguinis }>\text { jumlah profil plegmatis THEN } \\
\text { "Sangunis" }\end{array}$ & $\begin{array}{c}\text { TP02 } \\
\text { SANGUINIS }\end{array}$ \\
\hline 3 & $\begin{array}{l}\text { IF jumlah profil melankolis }>\text { jumlah profil sanguinis } \\
\text { AND jumlah profil melankolis }>\text { jumlah profil koleris } \\
\text { AND jumlah profil melankolis }>\text { jumlah profil plegmatis } \\
\text { THEN "Melankolis" }\end{array}$ & $\begin{array}{c}\text { TP03 } \\
\text { MELANKOLIS }\end{array}$ \\
\hline 4 & $\begin{array}{l}\text { IF jumlah profil plegmatis }>\text { jumlah profil koleris AND } \\
\text { jumlah profil plegmatis }>\text { jumlah profil melankolis AND } \\
\text { jumlah profil plegmatis }>\text { jumlah profil sanguinis THEN } \\
\text { "Koleris" }\end{array}$ & $\begin{array}{c}\text { TP04 } \\
\text { PLEGMATIS }\end{array}$ \\
\hline
\end{tabular}




\section{IMPLEMENTASI}

Hasil implementasi daripada system yang dibangun, sebagai berikut :

Bobot parameter (W) :

Gejala penting $\quad=5$

Gejala sedang / biasa $\quad=3$

Simililarity $($ problem case $)=$

$$
\operatorname{Similarity}(T S)=\frac{S 1 * W 1+S 2 * W 2+\ldots \ldots \ldots+S n * W n}{W 1+W 2+\ldots \ldots . .+W n}
$$

Pada percobaan pertama ini adalah mahasiswa atas nama Sri Devi Oktavia dengan bobot biasa 8 buah dan bobot penting 8 buah maka hasil pencarian adalah

a. Perhitungan kedekatan ciri Koleris

$$
\begin{aligned}
& =3 * 8+5 * 8 / 135 \\
& =24+40 / 135 \\
& =64 / 135=0,474 \\
& =47,4 \%
\end{aligned}
$$

b. Perhitungan kedekatan ciri Sanguinis

$$
\begin{aligned}
& =3 * 4+5 * 8 / 131 \\
& =12+40 / 131
\end{aligned}
$$$$
=52 / 131=0,396
$$$$
=36,9 \%
$$

c. Perhitungan kedekatan ciri Melankolis

$$
\begin{aligned}
& =3 * 9+5 * 7 / 131 \\
& =27+35 / 131 \\
& =62 / 131=0,473 \\
& =47,3 \%
\end{aligned}
$$

d. Perhitungan kedekatan ciri Plegmatis

$$
\begin{aligned}
& =3 * 10+5 * 2 / 121 \\
& =30+10 / 121 \\
& =40 / 121=0,330 \\
& =33,0 \%
\end{aligned}
$$

Dari pencarian similarity metode Case Based Reasoning (CBR) dapat hasil dengan persentase masingmasing kepribadian adalah koleris 47,4 \%, sanguinis 36,9 \%, melankolis 47,3\% dan plegmatis 33,0 \%. Maka dapat disimpulkan bahwa sampel diatas adalah berkepribadian Koleris, hal ini cocok dengan perhitungan dengan web sistem pakar.

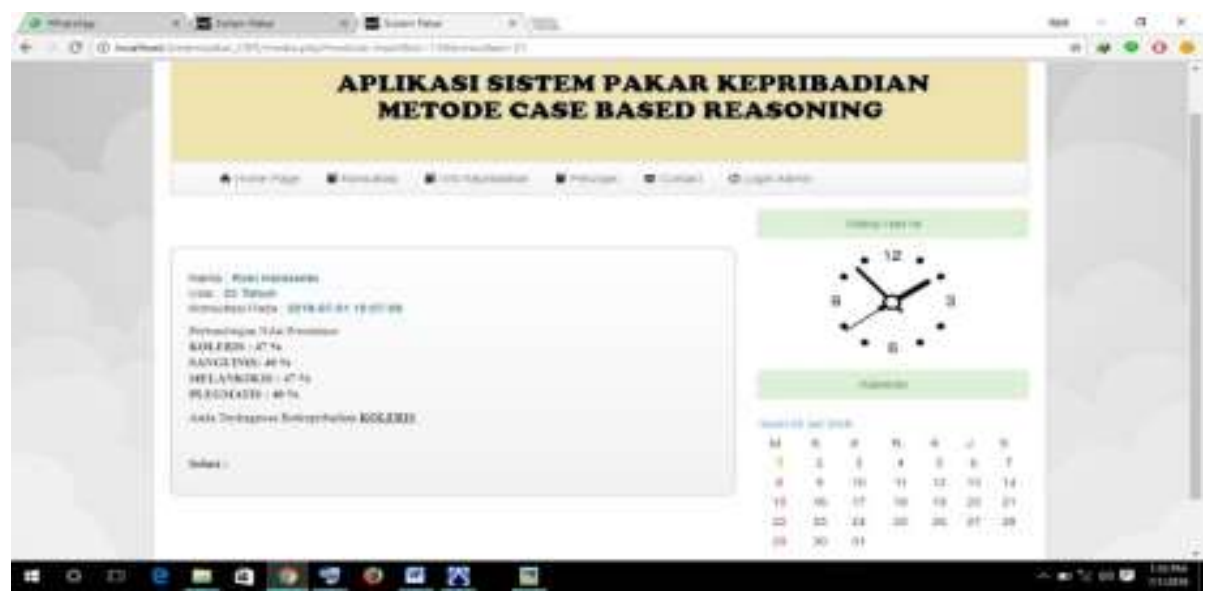

Gambar 1. Hasil Pengukuran Kepribadian

Dari hasil rancang bangun system pakar penentuan kepribadian maka antar muka yang dibangun adalah sebagai berikut : 


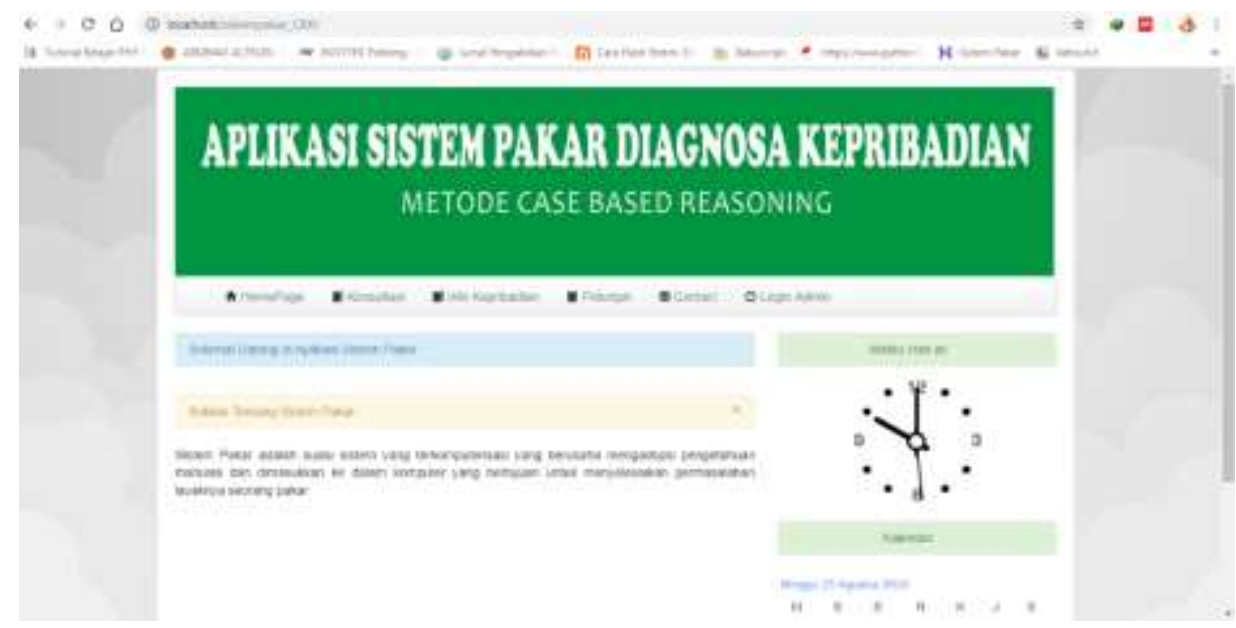

Gambar 2. Halaman Beranda

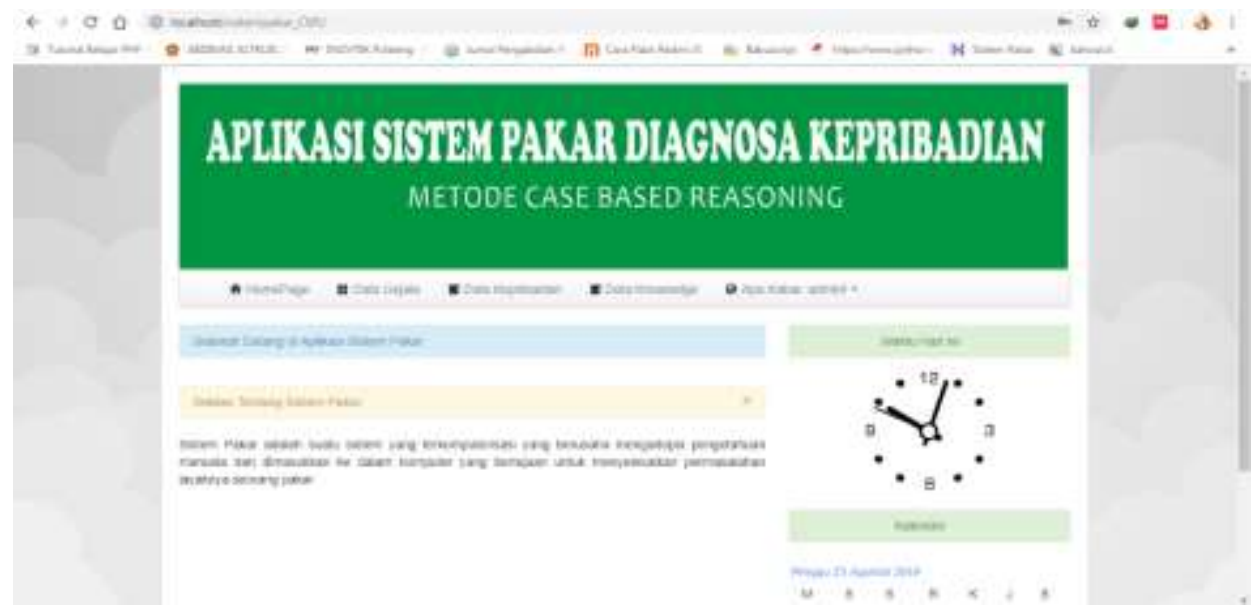

Gambar 3. Halaman Admin

\section{KESIMPULAN}

Dari hasil penelitian yang berjudul "Rancang Bangun Sistem Pakar Penentuan Kepribadian" dapat ditarik kesimpulam sebagai berikut :

1. Berdasarkan hasil diagnosa psikolog tentang kepribadian yang dikoversikan kedalam system komputer sangat bisa membantu psikolog dalam melakukan diagnosa kepribadian.

2. Sistem pakar penentuan kepribadian dengan metode case based reasoning (cbr) hasil nya komplek

3. Bobot nilai gejala kepribadian bisa berubah dari waktu ke waktu tergantung keilmuan psikologi.

4. Dengan system pakar basis desktop dan di jaringan internet hasilnya bisa tidak akurat

5. Perlu pendampingan psikolog dalam konsultasi kepribadian

\section{REFERENCES}

[1] C. A. S. E. Ased et al., "Gambar 1 . Struktur Sistem Pakar ( Sutoyo , 2011 ) sebagai Representasi Pengetahuan Setiap rule terdiri dari dua bagian, yaitu bagian IF disebut evidence ( Fakta- fakta ) dan bagian THEN disebut Hipotesis atau kesimpulan . ( Sutoyo , IF E THEN H E : Evid,” vol. 5, no. 1, pp. 41-47, 2017.

[2] S. Dalis, "Rancang Bangun Sistem Informasi Lembaga Penelitian Dan Pengabdian Masyarakat Berbasis Web," Paradig. - J. Komput. dan Inform., vol. 19, no. 1, pp. 1-8, 2017.

[3] W. Supartini and H. Hindarto, "Sistem Pakar Berbasis Web Dengan Metode Forward Chaining Dalam Mendiagnosa Dini Penyakit Tuberkulosis Di Jawa Timur," Kinetik, vol. 1, no. 3, p. 147, 2016.

[4] H. T. Sihotang, "Sistem Pakar Mendiagnosa Penyakit Kolesterol Pada Remaja Dengan Metode Certainty Factor (Cf) Berbasis Web," J. Mantik Penusa, vol. 15, no. 1, pp. 16-23, 2014.

[5] F. N. Salisah, L. Lidya, S. Defit, J. S. Informasi, F. Sains, and U. I. N. Suska, "Sistem Pakar Penentuan Bakat Anak Dengan Menggunakan Metode Forward Chaining,” J. Rekayasa dan Manaj. Sist. Inf., vol. 1, no. 1, pp. 62-66, 2015. 